\title{
The Role of Perceived Relevance and Attention in Teachers' Attitude and Intention to Use Educational Video Games
}

\author{
https://doi.org/10.3991/ijet.v12i03.6505 \\ Antonio Sánchez-Mena \\ Universidad Europea de Valencia, Valencia, Spain. \\ Universidad Europea de Canarias, Tenerife, Spain \\ antonio.sanchezmena@universidadeuropea.es \\ José Martí-Parreño \\ Universidad Europea de Valencia, Valencia, Spain \\ jose.marti@universidadeuropea.es \\ Joaquín Aldás-Manzano \\ Universitat de València, Valencia, Spain \\ joaquin.aldas@uv.es
}

\begin{abstract}
Educational video games (EVGs) are becoming a trending topic in education as a new teaching methodology which can help teachers to increase students' attention and engagement during the learning process. Nevertheless, despite an increasing academic interest in EVGs little research has been devoted to delve into teacher's beliefs affecting their attitude towards EVGs and how these beliefs also affect their intention to use EVGs in their courses. Using Keller's ARCS model as a theoretical framework, the role of perceived relevance and attention in teachers' attitude and intention to use EVGs is analyzed. To do so a research model is tested using a sample of 312 Higher Education teachers via structural equation modeling to predict teachers' attitude and behavioral intention to use EVGs in their courses. Results suggest that perceived attention drawn by EVGs is a factor affecting teachers' intentions to use EVGs in their courses. Perceived relevance was not found to affect directly neither attitude nor intention to use while teachers' perceived attention was found to affect teachers' perceived relevance of EVGs. Limitations of the study, implications for managers, and future research lines are addressed at the end of the paper.
\end{abstract}

Keywords-Educational video games, Higher Education, Intention to Use, Relevance. 


\section{Introduction}

\subsection{The gamification of education and educational videogames (EVGs)}

Gamification has been defined by Deterding et al. [1, p. 9] as 'the use of game design elements in non-game contexts' and is attracting interest among teachers as a way to increase students' attention and engagement during the learning process. Game elements and game dynamics are now widely used in areas such as business, healthcare or entertainment in a context that has been described by Deterding et al. [1] as the ludification of culture. Education is one of such areas in which the interest for gamification is gaining momentum. In fact, research on gamification published in top academic journals has increased times five over the last five years [2]. The gamification of education has been defined as 'the use of game elements in a learning environment' [3, p. 3] and extant literature shows that gamification has been used in a wide range of areas and subjects including energy education [4], veterinary education [5], citizenship education [6] or nanotechnology education [7]. Extant literature suggests that especially educational video games (EVGs) represent a promising tool in gamification. Among the reasons that have been pointed out for the use of video games in education is that EVGs may be appealing and motivating for the new generations of students that have grown up in the age of video games [8]. It is assumed that the elements that make video games fun along with the nature of games themselves are intrinsically motivating [9] so applying game elements to the classroom may increase students' intrinsic motivation to learn [10]. The use of video games can also improve students' engagement and learning outcomes [11] and can be used to tailor difficulty progression that facilitates scaffolded instruction based on each individual student's needs [10]. Video games offer a visual display of progress -e.g. badges[12] and give students the freedom to fail without fear when learning [13]. Trial-anderror process which makes mistakes recoverable can also be favoured by games [10].

Van Eck [14] summarizes the use of video games in education in three main strategies: a) the use of commercial off-the-shelf videogames (COTS) that take advantage of the existence of contents in these games that can be used for educational purposes, b) the use of serious games -a type of video games developed with non-recreational purposes where learning is the primary goal-, and c) to make students build their own games allowing the development of problem-solving abilities, programming skills, and game design skills. Examples of the use of commercial off-the-shelf videogames include the use of a MMORPG (Massively Multiplayer Online Role-Playing Game) such as World of Warcraft to increase students' social competence [15] or the use of SimCity to strengthen leadership decision-making [16] and RollerCoaster Tycoon 3 to support student learning of systems thinking [17]. Serious games have been defined as "video games (VGs) intended to serve a useful purpose" [18, p. 207] where the useful purpose is learning. Examples of the use of serious games include Blokify which was developed to enhanced students' competencies related to three-dimensional figures and their bidimensional representation by the standard views and perspective [19]. Other examples of serious games are ETIOBE Mates which was developed to improve children's nutritional knowledge [20] and ECOPET which was developed to 
educate learners to use home-energy conservatively [21]. Finally, one example of making students to build their own video games as part of their learning process is the case provided by Yang and Chang [22] where students designed digital games based on biology course content to increase retention of both course content and critical thinking skills.

\subsection{Teachers' motivational drivers to use EVGs}

Most of previous research on EVGs has focused in analysing the effectiveness of EVGs to achieve different learning outcomes (for a meta-analytic review see: [23], [24]). There are few studies that have explored factors driving teachers' attitude and behavioural intention to use EVGs in their courses. Nevertheless, teachers are key agents in the teaching-learning process [25] and teachers play a key role in introducing pedagogical innovations in the classroom, especially technology-related innovations [26]-[27] such as EVGs. Therefore gaining a deeper knowledge of teachers' attitude and behavioural intention to use EVGs will help managers of Higher Education institutions to better design Teacher Training Programs aiming to encourage teachers using EVGs in their courses.

This study is focused on two potential drivers of teachers' attitude and behavioural intention to use EVGs: i) teachers' beliefs about the capacity of gamification to draw students' attention to the learning materials (attention), and ii) teachers' perceived relevance of EVGs to deliver learning content (relevance).

This paper structures as follows: firstly, we present the research objectives. Secondly, we review Keller's ARCS model [28] to posit the hypotheses and the research model. Thirdly, we present the method used and the results. Finally, we address discussion, conclusions, managerial implications, limitations of the study and future research lines.

\section{$2 \quad$ Objectives}

The main objective of this study is to fill a research gap in the academic literature on gamification related to EVGs. More specifically we focused on the effect of two motivational drivers (attention and relevance) on teachers' attitude and behavioural intention to use EVGs. The specific objectives of our research are as follows:

- To test the effect of attention and relevance on teachers' attitude towards EVGs.

- To test the effect of attention and relevance on teachers' behavioral intention to use EVGs in their courses.

- To test the effect of attention on teachers' perceived relevance of EVGs.

- To test the effect of teachers' attitude towards EVGs on teachers' behavioral intention to use EVGs in their courses. 


\section{$3 \quad$ Hypotheses and Research model}

\subsection{Keller's ARCS model}

Keller's ARCS model [28] is one of the most widely mentioned theories of motivation used in education. In fact the ARCS model has been broadly used to evaluate and design instructional programs' motivational stimuli [29]- [30]-[31]-[32]. It has been suggested that Keller's ARCS model should become the standard by which the game increases learning motivation [33] and Keller's ARCS model has been previously tested in computer-based learning [34] and gamification contexts [35]-[36]-[37]. Therefore, it is widely accepted that Keller's ARCS model is suitable to investigate motivational issues in gamification contexts [38].

As all motivation theories, Keller's ARCS model assumes that individuals are motivated to the extent that their behavior is expected to lead to desired outcomes [39]. The expected outcome is derived from the expectancy-value theory [40]-[41] which assumes that people are motivated to engage in an activity "if it is perceived to be linked to the satisfaction of personal needs (the value aspect), and if there is a positive expectancy for success (the expectancy aspect)" [28, p. 3]. Human behavior is then "a compound function of perceived probability for success (expectancy) and perceived impact of the success (value)" [42]. Motivation is therefore a result of an interaction between a situation and an individual and "it is premised on an individual's desire for change, which is situationally driven” [35, p. 271]. Keller's ARCS model uses a multidimensional approach to measure the motivational drivers of individuals focusing on: i) attention, ii) relevance, iii) confidence (control), and iv) satisfaction. The relevance of teaching materials in students' future performance and the capacity of teaching materials to draw students' attention are considered key factor in the learning process.

\subsection{Relevance and attitude}

Relevance indicates both the process and the value of the learning content to the learner [28]. Relevance does not have to come just from the content itself but also from the way something is taught [28]. We conceptualize relevance as teachers' beliefs that gamification will provide learning value to students and that value comes both from materials used and the way the learning content is taught (gamification approach). The relationship between perceived value (relevance) and attitude has a long tradition in the expectancy-value theory [40]-[41]. Therefore we posit the following hypothesis:

H1: teachers' perceived relevance of EVGs will positively affect teachers' attitude towards EVGs. 


\subsection{Attention and attitude}

Keller's ARCS model assumes that media can moderate learners' attention and curiosity, this is, different media can increase attention and curiosity in different degree. Drawing attention to the learning materials (e.g. novelty in innovative learning materials such as gamified activities) might therefore increase students' motivation to learn. From a teachers-focused approach we conceptualize attention as teachers' beliefs that gamification will help them to draw learners' attention to the learning materials. Players' attention in game-based learning has been found to be correlated to learning effects [43]. In a study conducted by Wang [44] using Kahoot! students reported that they got more engaged in the lecture "when it was spiced up with something fun and exciting that made it possible to keep or re-establish the attention" [44, p. 224]. We assume that if teachers perceive that gamification has positive learning outcomes in their students this belief will affect teachers' attitude towards gamification. Therefore the following hypothesis is posited:

H2: teachers' beliefs of EVGs capacity to draw students' attention will positively affect teachers' attitude towards EVGs.

\subsection{Attention and relevance}

As far as we know no previous research has tested the relationship between attention and relevance in the ARCS framework. We assume that teachers' beliefs of gamification capacity to draw students' attention to the learning materials and activities will affect teachers' perceived relevance of gamification in their courses because the capacity of drawing students' attention in the learning process is a desirable outcome for teachers. Therefore, the following hypothesis is posit:

H3: teachers' beliefs of EVGs capacity to draw students' attention will affect teachers' perceived relevance of EVGs.

\subsection{Attention and intention to use}

Previous research has found that gamified learning draw learners' attention and was a strong predictor for learning achievement [35]. We assume that teachers' beliefs that gamification has a positive effect in attracting students' attention will affect teachers' intention to use gamification in their courses. Therefore, the following hypothesis is posit:

H4: teachers' beliefs of gamification capacity to draw students' attention will affect teachers' intention to use gamification.

\subsection{Relevance and intention to use}

To the best of our knowledge no previous research has tested the effect of perceived relevance on behavioural intentions. We assume that teachers' perception of EVGs relevance on students learning outcomes, this is, using EVGs will benefit their 
learning outcomes, will lead teachers to show a positive behavioural intention to use EVGs. Therefore, the following hypothesis is posit:

H5: teachers' perceived relevance of EVGs has a positive influence on teachers' behavioural intention to use EVGs in their courses.

\subsection{Attitude and intention to use}

Attitude is the result of individual beliefs concerning the behaviour, the results of that behaviour, and the importance attached to such beliefs. Social psychology literature clearly suggests that attitude has two components: affective and cognitive [45][46]. The affective component in attitude refers to how much a person likes the object of his thoughts [47] and measures the degree of emotional attraction to the object. The cognitive component refers to an individual's specific beliefs about the object [45] and consists in a value-based assessment, judgment, reception or perception of the object [46]. Behavioural intention is defined as 'an individual's subjective probability that he or she will perform a specified behaviour' [48, p. 288] and is a better predictor of actual behaviour than attitude when an intention has been formed [49]. Literature review clearly shows a direct and positive relation between a person's attitude towards an object or behaviour and that person's behaviour [50]. Previous research also suggest that attitude to use is a key factor influencing technology adoption behaviour [51]-[52]-[53] so the following hypothesis is posited:

H6: teachers' positive attitude towards EVGs has a positive influence on teachers' behavioural intention to use EVGs in their courses.

Figure 1 depicts a graphical representation of the research model.

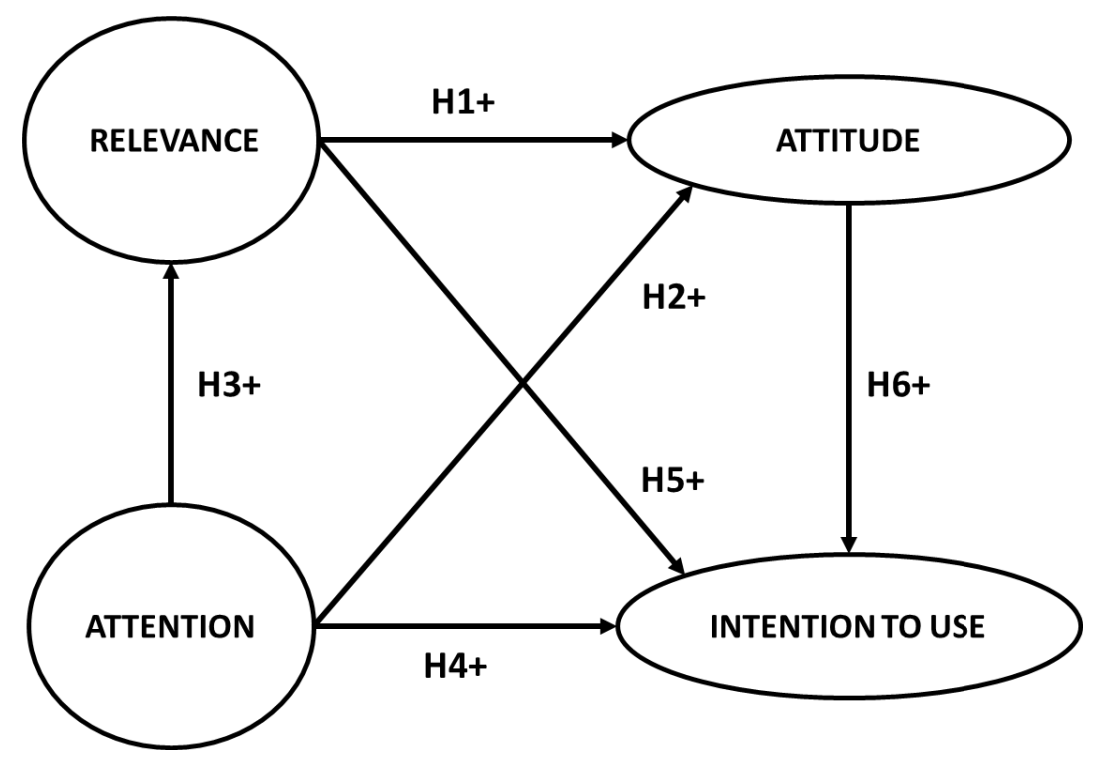

Fig. 1. Hypotheses and research model 


\section{$4 \quad$ Hypotheses and Research model}

\subsection{Participants}

A total of 312 teachers serving in Higher Education institutions were contacted via email and completed the online questionnaire. The age of the participants ranges between 26 and 65 years, with an average age of 42.8 years old while $52.4 \%$ of the respondents are males.

\subsection{Procedure and measurement instrument}

Data was gathered through an online questionnaire. Snowball sampling [54]-[55] was used for selection of respondents in this study. Although snowball sampling is unlikely to obtain a representative sample because there is no real control of the snowball effect [56] this form of sampling is often used in online questionnaires to target hard-to-reach population subgroups [57]. All items used to develop the questionnaire were adapted from existing scales: five items were adapted from [35] to measure attention; three items were adapted from [35] to measure relevance; three items were adapted from [58] to measure attitude towards gamification; and three items were adapted from [59] to measure intention to use gamification. All questionnaire items were measured using a 5-point Likert-type scale where $(1)=$ strongly disagree, and (5) = strongly agree.

Before testing the hypotheses, the psychometric properties of the measurement instrument were assessed. Tables 1 and 2 show the results for measurement model reliability, convergent validity, and discriminant validity. Indicators demonstrate the high internal consistency of the constructs. In each case, Cronbach's alpha [60] exceeded Nunnally and Bernstein's [61] recommendation of .70. Composite reliability represents the shared variance among a set of observed variables measuring an underlying construct [62]. Generally, a composite reliability of at least .70 is considered desirable [63]. This requirement is met for every factor. Average variance extracted (AVE) was also calculated for each construct, resulting in AVEs greater than .50 [62]. As evidence of convergent validity, results indicate that all items are significantly $(p<.01)$ related to their hypothesized factors, and the size of all the standardized loadings are higher than .60 [63].

Evidence for discriminant validity of the measures (Table 2) was tested checking that the shared variance between pairs of constructs was always less than the corresponding AVE [62]. We also apply the criterion proposed by Henseler, Ringle and Sarstedt [64] according to which the HTMT ratio should be lower than .90. No special problems arise. On the basis of these criteria, we concluded that the measures in the study provided sufficient evidence of reliability, convergent and discriminant validity. 
Table 1. Reliability and convergent validity

\begin{tabular}{clccccc}
\hline \multirow{2}{*}{ Factor } & ITEM & $\begin{array}{c}\text { Standardized load- } \\
\text { ing }\end{array}$ & $\begin{array}{c}\text { t value (boot- } \\
\text { strap) }\end{array}$ & CA & CR & AVE \\
\hline Attention & ATTE1 & $0.91^{* *}$ & 44.9 & 0.94 & 0.96 & 0.82 \\
& ATTE2 & $0.94^{* *}$ & 69.2 & & & \\
& ATTE3 & $0.90^{* *}$ & 44.1 & & & \\
& ATTE4 & $0.93^{* *}$ & 60.0 & & & \\
\multirow{5}{*}{ Attitude } & ATTE5 & $0.84^{* *}$ & 25.2 & & & \\
& ATT1 & $0.94^{* *}$ & 65.3 & 0.95 & 0.97 & 0.92 \\
& ATT2 & $0.98^{* *}$ & 201.6 & & & \\
& ATT3 & $0.95^{* *}$ & 64.0 & & & \\
\multirow{5}{*}{ Relevionce } & INT1 & $0.91^{* *}$ & 62.8 & 0.87 & 0.92 & 0.79 \\
& INT2 & $0.92^{* *}$ & 58.3 & & & \\
& INT3 & $0.84^{* *}$ & 21.4 & & & \\
& REL1 & $0.89^{* *}$ & 50.6 & 0.84 & 0.90 & 0.76 \\
& REL2 & $0.81^{* *}$ & 19.6 & & & \\
\hline
\end{tabular}

** $\mathrm{p}<0.01$

Note: $\mathrm{CA}=$ Cronbach's alpha; $\mathrm{CR}=$ Composite reliability; $\mathrm{AVE}=$ Average Variance Extracted

Table 2. Discriminant validity

\begin{tabular}{lcccc}
\hline \multicolumn{1}{c}{ Factor } & F1 & F2 & F3 & F4 \\
\hline F1. Attention & 0.90 & 0.69 & 0.81 & 0.82 \\
F2. Attitude & 0.66 & 0.96 & 0.88 & 0.65 \\
F3. Intention & 0.73 & 0.81 & 0.89 & 0.74 \\
F4. Relevance & 0.83 & 0.59 & 0.63 & 0.87 \\
\hline
\end{tabular}

Note: diagonal, square root of AVE; Lower triangle: latent variable correlations

Upper triangle: HTMT ratio

\section{$5 \quad$ Results}

Table 3 shows the results of the estimation of the research model. Results indicate that attention influences attitude in a significant and positive way $(\mathrm{H} 2 ; \beta=0.54 ; \mathrm{p}$ $<.01$; Accepted). Results also indicate that attention influences relevance in a significant and positive way $(\mathrm{H} 3 ; \beta=0.83 ; \mathrm{p}<.01$; Accepted). Attention also influences intention to use in a significant and positive way (H4; $\beta=0.81 ; \mathrm{p}<.01$; Accepted). Relevance was not found to influence attitude towards gamification $(\mathrm{H} 1 ; \beta=0.14 ; \mathrm{p}$ $<.01$; Rejected) nor intention ( $\mathrm{H} 5 ; \beta=0.01 ; \mathrm{p}>.05$; Rejected). Attitude was found to significantly influence intention (H6; $\beta=0.58 ; \mathrm{p}<.01$; Accepted) 
Table 3. Hypotheses testing

\begin{tabular}{lcc}
\hline \multicolumn{1}{c}{ Hypothesis } & Standardized beta & t value (bootstrap) \\
\hline H1. Relevance-->Attitude & 0.14 & 1.34 \\
H2. Attention-->Attitude & $0.54^{* *}$ & 4.81 \\
H3. Attention --> Relevance & $0.83^{* *}$ & 25.87 \\
H4. Attention-->Intention & $0.34^{* *}$ & 4.37 \\
H5. Relevance-->Intention & 0.01 & 0.07 \\
H6. Attitude-->Intention & $0.58^{* *}$ & 11.11 \\
\hline
\end{tabular}

$* * \mathrm{p}<0.01$

$\mathrm{R}^{2}($ Attitude $)=0.44 ; \mathrm{R}^{2}$ (Relevance) $=0.69 ; \mathrm{R}^{2}$ (Intention $)=0.72$

$\mathrm{Q}^{2}($ Attitude $)=0.37 ; \mathrm{Q}^{2}($ Relevance $)=0.53 ; \mathrm{Q}^{2}($ Intention $)=0.48$

Figure 2 depicts a graphical representation of the results.

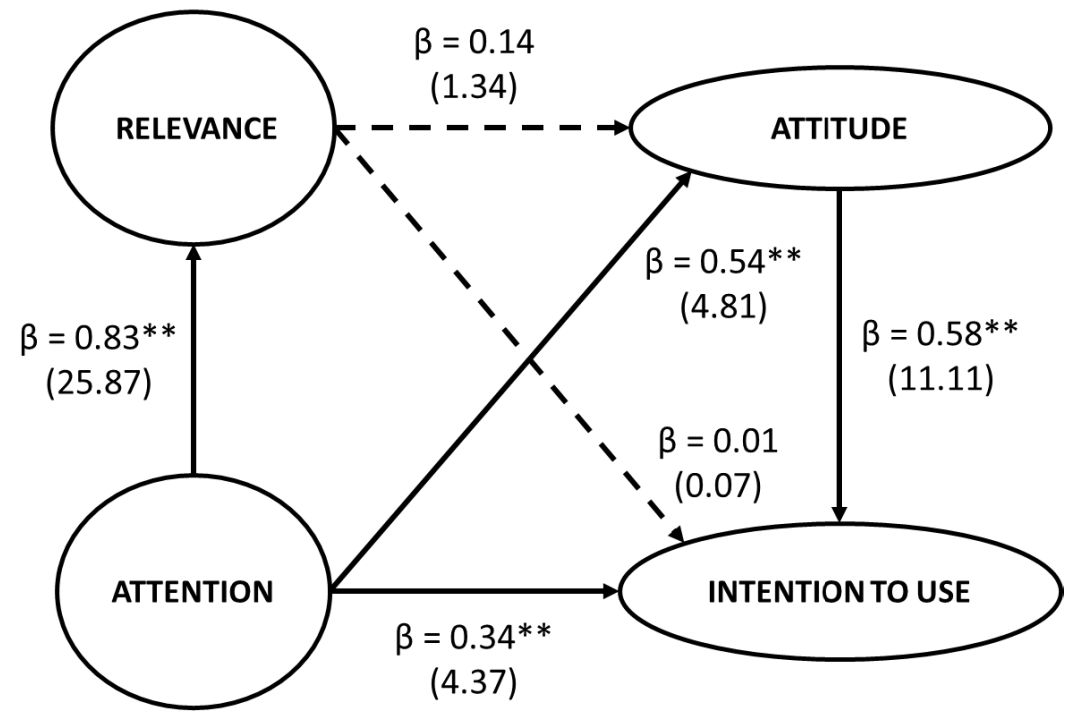

Fig. 2. Results

\section{Discussion}

The results of this study suggest the important role of attention both in attitude and intention to use EVGs. Broadly speaking, teachers believing that EVGs can be used to draw students' attention have a positive attitude towards EVGs and also have intention to use EVGs. Attention also affects teachers' perceived relevance of EVGs, this is, teachers' beliefs in the capacity of EVGs to draw students' attention seem to affect teachers' perceived relevance of EVGs in their courses. Surprisingly teachers' perceived relevance was not found to affect neither teachers' attitude towards EVGs nor teachers' intention to use EVGs. Why teachers' perceived relevance of EVGs is not 
affecting their attitudes and behavioral intentions, as expected, deserves a deeper attention in future research. One possible explanation is that teachers found easier to value EVGs as an attention driver than as a relevant teaching methodology for students learning process. This finding alerts though a possible future risk for a spurious use of EVGs, this is, teachers will use EVGs just for driving students' attention to the learning material without really believing that EVGs can provide intrinsic learning value.

\section{Conclusions, limitations and future research}

s gamification is attracting an increasing attention among teachers as a means to motivate and to engage students in their learning process more research is needed to better understand factors affecting teachers' attitude and intention to use EVGs in their courses. This study analyses two key factors in motivation to learning (attention and relevance) as antecedents of teachers' attitude towards EVGs and teachers' behavioral intention to use EVGs in their courses. Our results suggest that teachers' beliefs in EVGs capacity to draw students' attention play a key role in both teachers' attitude towards EVGs and teachers' behavioral intention to use EVGs in their courses. Moreover, attention also affects teachers' perceived relevance of EVGs in students learning process. These results suggest that a great attention must be paid to all design elements in EVGs as teachers seem to rely in EVGs as eye-catchers to gauge students' attention. Which EVGs design features are able to catch students' attention (for example, visual elements such as images or animations) deserves therefore further research. Game dynamics can also be used to draw students' attention, so future research should also delve into which game dynamics (for example, badges and rewards) can be more effectively used to draw students' attention. One surprising result of this study is that, unexpectedly, perceived relevance was not found to influence neither teachers' attitude towards EVGs nor teachers' intention to use EVGs. Maybe teachers' core beliefs regarding EVGs are that catching students' attention using EVGs will be enough to achieve positive learning outcomes but teachers are less confident in how EVGs per se are relevant as teaching materials to be successfully used with their students. Future research should focus on this EVGs for drawing students' attention versus EVGs as relevant teaching materials using a qualitative approach to better understand the underlying mechanisms shaping teachers' perceptions about EVGs real performance as teaching materials.

One main limitation of this study is the convenience sample used. Although a sample of 312 Higher Education institutions teachers is big enough for exploratory research the convenience sample used does not allow for generalization of our findings. Future research should use a representative sample of Higher Education institutions teachers in order to generalize these findings to the target population. It is well known that there are gender differences in video games attitude and usage so future research should analyze the moderating role of gender in both attitude towards EVGs and intention to use EVGs. 
Paper-The Role of Perceived Relevance and Attention in Teachers' Attitude and Intention to Use Edu...

\section{Acknowledgement}

This work was supported by Laureate International Universities through the David A. Wilson Award for Excellence in teaching and learning under grant LIU-WIL2015.

\section{References}

[1] S. Deterding, D., Dixon, R. Khaled and L. Nacke, "From game design elements to gamefulness: defining gamification", in Proc. of the 15th Int. Academic MindTrek Conf.: Envisioning Future Media Environments, 2011, pp. 9-15.

[2] J. Martí-Parreño, E. Méndez-Ibáñez and A. Alonso-Arroyo, "The Use of Gamification in Education: A Bibliometric and Text Mining Analysis", J. of Comput. Assisted Learning, vol. 32, pp. 663-676, 2016. https://doi.org/10.1111/jcal.12161

[3] J. Simões, R. D. Díaz Redondo, and A. F. Fernández Vilas, “A social gamification framework for a K-6 learning platform" Comput. in Human Behavior, vol. 29/2, pp. 345-353, 2013. https://doi.org/10.1016/j.chb.2012.06.007

[4] J.C. Yang, K.H. Chien and T.C. Liu, "A digital game-based learning system for energy education: An energy conservation pet", The Turkish Online J. of Educational Technology, vol. 11/2, pp. 27-37. 2012.

[5] M.H. De Bie and L.J.A. Lipman, "The Use of Digital Games and Simulators in Veterinary Education: An Overview with Examples”, J. of Veterinary Medical Educ., vol. 39/1, pp. 13-20, 2012. https://doi.org/10.3138/jvme.0511.055R

[6] K.Y. Lim and M.Y. Ong, "The rise of Li' Ttledot: A study of citizenship education through game-based learning", Australasian J. of Educational Technology, vol. 28/8, pp. 1420 1432, 2012. https://doi.org/10.14742/ajet. 779

[7] R. Blonder and S. Sakhnini, "Teaching two basic nanotechnology concepts in secondary school by using a variety of teaching methods", Chemistry Educ. Research and Practice, vol. 13/4, pp. 500-516, 2012. https://doi.org/10.1039/C2RP20026K

[8] Glover, "Play as you learn: gamification as a technique for motivating learners", Herrington, J. et al. (Eds.). Proc. of World Conf. on Educational Multimedia, Hypermedia and Telecommunications, Chesapeake, VA, 2013, pp. 1999-2008.

[9] D.M. Adams, R.E. Mayer, A. MacNamara, A. Koenig and R. Wainess, "Narrative games for learning: Testing the discovery and narrative hypotheses", J. of Educ. Psychology, vol. 104/1, pp. 235-249, 2012. https://doi.org/10.1037/a0025595

[10] M.D. Hanus and J. Fox, "Assessing the effects of gamification in the classroom: A longitudinal study on intrinsic motivation, social comparison, satisfaction, effort, and academic performance", Comput. \& Educ., vol. 80, 152-161, 2015. https://doi.org/10.1016/j.comp edu.2014.08.019

[11] D.B. Clark, B.C. Nelson, H.Y. Chang, M. Martínez-Garza, K. Slack and C.M. D’Angelo, "Exploring Newtonian mechanics in a conceptually-integrated digital game: Comparison of learning and affective outcomes for students in Taiwan and the United States", Comput. \& Educ., vol. 57/3, pp. 2178-2195, 2011. https://doi.org/10.1016/j.compedu.2011.05.007

[12] K.M. Kapp, The gamification of learning and instruction: Game-based methods and strategies for training and education. San Francisco: Pfieffer, 2012.

[13] J.J. Lee and J. Hammer, "Gamification in education: What, How, Why Bother?", Academic Exchange Quart., vol. 15/2, pp. 146-151, 2011.

[14] R. Van Eck, "Digital Game-Based Learning: It's Not Just the Digital Natives Who Are Restless”, EDUCAUSE Review, vol. 41/2, pp. 16-30, 2006. 
[15] M. Visser, M. L. Antheunis and A. P. Schouten, "Online communication and social wellbeing: how playing World of Warcraft affects players' social competence and loneliness", J. of Appl. Social Psychology, vol. 43/7, pp. 1508-1517, 2013. https://doi.org/10.1111/ jasp. 12144

[16] H.W. Lin and Y-L. Lin, "Digital educational game value hierarchy from a learners' perspective." Comput. in Human Behavior, 30, pp. 1-12, 2014. http://dx.doi.org10.1016/j.chb.2013.07.034

[17] M. Shah and A. Foster, "Undertaking an Ecological Approach to Advance Game-Based Learning: A Case Study”, J. of Educational Technology and Soc., vol. 17/1, 29-41, 2014.

[18] C. Girard, J. Ecalle and A. Magnan, "Serious games as new educational tools: how effective are they? A meta-analysis of recent studies", J. of Comput. Assisted Learning, vol. 29/3, 207-219, 2013. https://doi.org/10.1111/j.1365-2729.2012.00489.x

[19] J.L. Saorin, J. De la Torre Cantero, D.M. Díaz, C. Meier and D.R.: Trujillo, "Blokify: Juego de modelado e impresión 3D en tableta digital para el aprendizaje de vistas normalizadas y perspectiva", Digital Educ. Review, vol. 27, pp. 105-121, 2015.

[20] R. M. Baños, A. Cebolla, E. Oliver, M. Alcañiz, and C. Botella, "Efficacy and acceptability of an Internet platform to improve the learning of nutritional knowledge in children: the ETIOBE mates", Health Educ. Research, vol. 28/2, pp. 234-248, 2013. https://doi.org/10.1093/her/cys044

[21] J.C. Yang, K.H. Chien and T.C. Liu, "A digital game-based learning system for energy education: An energy conservation pet", The Turkish Online J. of Educational Technology, vol. 11/2, pp. 27-37, 2012.

[22] Y.C. Yang and C. Chang, "Empowering students through digital game authorship: Enhancing concentration, critical thinking, and academic achievement" Comput. \& Educ., vol. 68, pp. 334-344, 2013. https://doi.org/10.1016/j.compedu.2013.05.023

[23] T. Sitzmann, "A meta - analytic examination of the instructional effectiveness of computer-based simulation games", Personnel Psychology, vol. 64/2, pp. 489-528, 2011. https://doi.org/10.1111/j.1744-6570.2011.01190.x

[24] E.A. Boyle, T. Hainey, T.M. Connolly, G. Gray, J. Earp, M. Ott, and J. Pereira, “An update to the systematic literature review of empirical evidence of the impacts and outcomes of computer games and serious games" Comput. \& Educ., vol. 94, pp. 178-192, 2016. https://doi.org/10.1016/j.compedu.2015.11.003

[25] G. Biesta, M. Priestley and S. Robinson, "The role of beliefs in teacher agency", Teachers and Teaching, vol. 21/6, pp. 624-640, 2015. https://doi.org/10.1080/13540602. 2015.1044325

[26] D.J. Ketelhut and C.C. Schifter, "Teachers and game-based learning: Improving understanding of how to increase efficacy of adoption”, Comput. \& Educ., vol. 56/2, pp. 539546, 2011. https://doi.org/10.1016/j.compedu.2010.10.002

[27] S. Mumtaz, "Factors affecting teachers' use of information and communications technology: a review of the literature", J. of Inform. Technology for Teacher Educ., vol. 9/3, pp. 319-342, 2000. https://doi.org/10.1080/14759390000200096

[28] J.M. Keller, "Development and Use of the ARCS Model of Motivational Design", J.of Instructional Develop., vol. 10/3, pp. 1-10, 1987.

[29] J.D. House, "Instructional activities and interest in science learning for adolescent students in Japan and the United States: findings from the third International Mathematics and Science Study (TIMSS)", Int. J. of Instructional Media, vol. 30, 429-443, 2003.

[30] M. Chang and J.D. Lehman, "Learning foreign language through an interactive multimedia program: an experimental study on the effects of the relevance component of the ARCS model", CALICO J., vol. 20, pp. 81-98, 2002. 
Paper-The Role of Perceived Relevance and Attention in Teachers' Attitude and Intention to Use Edu...

[31] S.H. Song and J.M. Keller, "Effectiveness of motivationally adaptive computer-assisted instruction on the dynamic aspects of motivation", Educ. Technology Research and Develop., vol. 49/2, pp. 5-22, 2001. https://doi.org/10.1007/BF02504925

[32] S. Wongwiwatthananukit and N.G. Popovich, "Applying the ARCS model of motivational design to pharmaceutical education", Amer. J. of Pharmaceutical Educ., vol. 64/2, pp. 188-196, 2000.

[33] Karoulis and S. Demetriadis, The motivational factor in educational games. Working paper D21, 2, 2005.

[34] W. Huang, W. Huang, H. Diefes - Dux and P.K. Imbrie, "A preliminary validation of Attention, Relevance, Confidence and Satisfaction model - based Instructional Material Motivational Survey in a computer - based tutorial setting", British J. of Educational Technology, vol. 37/2, pp. 243-259, 2006. https://doi.org/10.1111/j.1467-8535.2005.00582.x

[35] C.H. Su and C.H. Cheng, "A mobile gamification learning system for improving the learning motivation and achievements", J. of Comput. Assisted Learning, vol. 31/3, pp. 268286, 2015. https://doi.org/10.1111/jcal.12088

[36] J.V. Dempsey and B. Johnson, "The development of ARCS gaming scale”, J. of Instructional Psychology, vol. 5, 215-221, 1998.

[37] J.D. Klein, "Effect of instructional gaming and reentry status on performance and motivation”, Contemporary Educational Psychology, vol. 17, 364-370, 1992. https://doi.org/10.1016/0361-476X(92)90074-9

[38] H. Astleitner and C. Wiesner, "An integrated model of multimedia learning and motivation”, J. of Educational Multimedia and Hypermedia, vol. 13/1, pp. 3-21, 2004.

[39] S. Robbins, Organizational behavior. Upper Saddle River (NJ): Pearson Education, 2005.

[40] E.C. Tolman, Purposive behavior in man and animals. New York: Appleton-CenturyCrofts, 1932.

[41] Lewin, K., A dynamic theory of personality. New York: McGraw-Hill, 1935.

[42] W.H. Huang, W.Y. Huang and J. Tschopp, "Sustaining iterative game playing processes in DGBL: The relationship between motivational processing and outcome processing", Comput. \& Educ., vol. 55/2, pp. 789-797, 2010. https://doi.org/10.1016/j.compedu. 2010.03.011

[43] Y.K. Juan and T.W. Chao, "Game-Based Learning for Green Building Education", Sustainability, vol. 7/5, pp. 5592-5608, 2015. https://doi.org/10.3390/su7055592

[44] A.I. Wang, "The wear out effect of a game-based student response system", Comput. \& Educ., vol. 82, pp. 217-227, 2015. https://doi.org/10.1016/j.compedu.2014.11.004

[45] R.P. Bagozzi and R.E. Burnkrant, "Attitude organization and the attitude-behavior relationship: a reply to Dillon and Kumar", J. of Personality and Social Psychology, vol. 49, 116, 1985. https://doi.org/10.1037/0022-3514.49.1.47

[46] S. Chaiken and C. Stangor, "Attitudes and attitude change", Annu. Review of Psychology, vol. 38/1, 575-630, 1987. https://doi.org/10.1146/annurev.ps.38.020187.003043

[47] W.J. McGuire, "Attitudes and attitude change" in Handbook of Social Psychology, vol. 19, New York: Random House, 1985, pp. 233-346.

[48] M. Fishbein and I. Ajzen, Belief, attitude, intention and behavior: an introduction to theory and research. New York, NY: Addison-Wesley, 1975.

[49] P. R. Warshaw and F. D. Davis, "The accuracy of behavioral intention versus behavioral expectation for predicting behavioral goals", The J. of Psychology, vol. 119/6, pp. 599602, 1985. https://doi.org/10.1080/00223980.1985.9915469

[50] S.P. Brown and D.M. Stayman, "Antecedents and consequences of attitude toward the ad: A meta-analysis", J. of Consumer Research, vol. 19, pp. 34-51, 1992. https://doi.org/10.1086/209284 
Paper-The Role of Perceived Relevance and Attention in Teachers' Attitude and Intention to Use Edu...

[51] F.D. Davis, "A Technology Acceptance Model for Empirically Testing New End-User Information Systems: Theory and Results", Ph.D. dissertation, Massachusetts Institute of Technology, Cambridge, MA, 1985.

[52] F.D. Davis, R.P. Bagozzi and P.R. Warshaw, "User acceptance of computer technology: a comparison of two theoretical models", Manage. Sci., vol. 35/8, pp. 982-1003, 1989. https://doi.org/10.1287/mnsc.35.8.982

[53] Y. Kuo and S. Yen, "Towards an understanding of the behavioural intention to use $3 \mathrm{G}$ mobile value-added services", Comput. in Human Behavior, vol. 25, pp. 103-110, 2009. https://doi.org/10.1016/j.chb.2008.07.007

[54] L.A. Goodman, "Snowball sampling", The Annals of Mathematical Statistics, vol. 32/1, pp. 148-170, 1961. https://doi.org/10.1214/aoms/1177705148

[55] P. Biernacki and D. Waldorf, "Snowball sampling", Sociological Methods and Research, vol. 10/2, pp. 141-163, 1981.

[56] D. Hall and I.M. Hall, Practical Social Research: Project Work in the Community. London: Macmillan, 1996. https://doi.org/10.1007/978-1-349-24739-4

[57] G.R. Sadler, H.C. Lee, R.S.H. Lim and J. Fullerton, "Recruitment of hard-to - reach population subgroups via adaptations of the snowball sampling strategy", Nursing \& Health Sci., vol. 12/3, pp. 369-374, 2010. https://doi.org/10.1111/j.1442-2018.2010.00541.x

[58] Chattopadhyay and K. Basu, "Humor in advertising: the moderating role of prior brand evaluation”, J. of Marketing Research, vol. 27, pp. 466-476, 1990. https://doi.org/10.2307/ 3172631

[59] T.A. Shimp and A. Kavas, "The theory of reasoned action applied to coupon usage", J. of Consumer Research, vol. 11/3, pp. 795-809, 1984. https://doi.org/10.1086/209015

[60] L. Cronbach, "Coefficient alpha and the internal structure of tests", Psychometrika, vol. 16, pp. 297-334, 1951. https://doi.org/10.1007/BF02310555

[61] J. Nunnally and I. Bernstein, Psychometric theory, New York: McGraw-Hill, 1994.

[62] Fornell and D.F. Larcker, "Structural equation models with unobservable variables and measurement error: Algebra and statistics", J. of Marketing Research, vol. 18/3, pp. 328388, 1981.

[63] R.P. Bagozzi and Y. Yi, "On the evaluation of structural equation models", J. of the Academy of Marketing Sci., vol. 16/1, pp. 74-94, 1988. https://doi.org/10.1007/BF02723327

[64] J. Henseler, C.M. Ringle and M. Sarstedt, "A new criterion for assessing discriminant validity in variance-based structural equation modeling", J. of the Academy of Marketing Sci., vol. 43/1, pp. 115-135, 2014. https://doi.org/10.1007/s11747-014-0403-8

\section{Authors}

Antonio Sánchez-Mena is HR Manager at Universidad Europea de Valencia and Universidad Europea de Canarias, Spain. He is a PhD Student at Universidad Europea de Madrid. His main research interests include new methods and technologies applied to learning and development in order to improve performance of Faculty and nonFaculty Staff. He has been involved in R\&D projects funded by Eureka networks as an expert on Technology-enhanced learning.

José Martí-Parreño is Associate Professor at the Universidad Europea de Valencia, Spain. He got his PhD from the Polytechnic University of Valencia (2003) and from the University of Valencia (2015). His main research areas of interest are marketing communications and education innovation. His research has been published in 
top refereed journals and he serves as a reviewer in international journals. He was awarded in 2015 with the David A. Wilson Award for Excellence in Teaching and Learning for a research project in gamification. He is the Director of the Postgraduate Certificate in Education (PGCE) at Universidad Europea de Valencia.

Joaquín Aldás-Manzano is Full Professor at Universitat de València, Spain. His main research areas are consumer behaviour and quantitative research methods. His work has been published in top refereed journals such as European Journal of Marketing. He has published over a dozen of books and book chapters with world leading publishers such as Routledge Publishing House.

Article submitted 10 December 2016. Published as resubmitted by the authors 23 January 2017. 